\section{Reduction of Early Fruit Abscission by Main-branch-girdling in Macadamia Is Related to the Favorable Status of Carbohydrates and Endogenous Hormones}

\author{
Wei Hai Yang \\ College of Life Science and Resources and environment, Yichun University, \\ Yichun, Jiangxi, China; South Subtropical Crops Research Institute, CATAS, \\ Zhanjiang, Guangdong, China; and Key Laboratory of Tropical Fruit Biology, \\ Ministry of Agriculture, Zhanjiang, Guangdong, China \\ Chao Zhong Lu \\ South Subtropical Crops Research Institute, CATAS, Zhanjiang, Guangdong, \\ China, and Key Laboratory of Tropical Fruit Biology, Ministry of Agriculture, \\ Zhanjiang, Guangdong, China \\ Wei Chen and Huan Yu Xu \\ College of Agriculture and Horticulture, Jiangsu Polytechnic College of \\ Agriculture and Forestry, Zhenjiang, Jiangsu, China \\ Additional index words. fruit set, carbon availability, phytohormone balance
}

\begin{abstract}
Fruit abscission occurring severely in the early fruit development affects macadamia yield. Developing effective methods to improve fruit retention is a priority for macadamia cultivation and production. Girdling is an important horticultural practice that has been widely used to increase fruit yield. Previous studies have shown that girdling fails to increase macadamia yield despite enhancing the early fruit set, but few have examined the effect of girdling on its related physiological mechanism. The objective of this study was to investigate the effects of main-branch girdling (MBG) on early fruit retention and also on the levels of carbohydrates and endogenous hormones in the leaves, bearing shoots and fruit of macadamia. Herein, MBG was performed at fruit set using a single-blade knife on 9-year-old macadamia trees (Macadamia integrifolia). Results showed that MBG significantly reduced young fruit drop, concurrent with significant increases in the contents of starch in both the leaves and the bearing shoots and in glucose, fructose, and sucrose levels in the husk and seed. It was suggested that the availability of carbohydrate for fruit retention was improved by MBG. Additionally, MBG increased indole-3-acetic acid (IAA), gibberellin ( $\left(\mathrm{GA}_{3}\right)$, and zeatin-riboside ( $\mathrm{ZR}$, a type of cytokinin) concentrations and decreased abscisic acid (ABA) contents in the husk and the seed, indicating that MBG reduced the early fruit drop by modifying the balance of endogenous hormones. Therefore, a positive interplay between carbohydrates and endogenous hormones induced by MBG was involved in the reduction of early fruit abscission in macadamia.
\end{abstract}

Received for publication 8 Aug. 2021. Accepted for publication 24 Sept. 2021.

Published online 14 December 2021.

This work was financially supported by the National Natural Science Foundation of China $(32060652$ and 31572082), the Science and Technology Research Project of Education Department of Jiangxi Province (GJJ190847), and the Integrated Demonstration of Key Techniques for the Industrial Development of Featured Crops in Rocky Desertification Areas of Yunnan-Guangxi-Guizhou Provinces (SMH2019-2021) and college-level scientific research project of Jiangsu Vocational College of Agriculture and Forestry (2020kj008).

We thank Wenqiu Lin for providing necessary techniques to conduct the experiments.

H.Y.X. is the corresponding author. E-mail: hyxu324@163.com.

This is an open access article distributed under the CC BY-NC-ND license (https://creativecommons. org/licenses/by-nc-nd/4.0/).
$<3 \%$ of the yield of macadamia in the world (Ning et al., 2019).

Like many tropical trees, macadamia is mass flowering. A mature tree in a season can produce more than 10,000 racemes each consisting of 100 to 300 flowers (Ito, 1980). However, more than $90 \%$ of the flowers with unsuccessful fertilization are abscised in the first 2 weeks after anthesis (Sakai and Nagao, 1985; Trueman and Turnbull, 1994a). Following this initial drop, more than $80 \%$ of the immature fruit are abscised during the 3 to 8 weeks postanthesis (Trueman and Turnbull, 1994b; Wallace et al., 1996). This problem of the excessive fruitlet drop also occurred commonly in macadamia orchards across the production regions in China, such as Guangdong (Xu et al., 1995), Yunnan (Tao et al., 2005), and Guangxi (Zheng et al., 2011). Thus, this phenomenon has posed a major challenge to the development of the macadamia industry.

Studies on cherry (Blanusa et al., 2006), apple (Zhu et al., 2011), litchi (Kuang et al., 2012), and citrus (Talon et al., 1997; GómezCadenas et al., 2000; Mahouachi et al., 2009) confirmed the close relationship between the carbohydrate availability to the developing fruitlets and their likelihood of abscission. The immature fruit abscission in macadamia was presumably caused by a shortage of available carbohydrates for rapid fruit development (McFadyen et al., 2011, 2012a, $2012 b$ ). Furthermore, fruit set and fruit development are initiated by the phytohormones signals (Goetz et al., 2007; Picken, 2015). Gibberellins (GAs) and cytokinin (CTK) were considered as the positive regulators in fruit set and development (Iglesias et al., 2007; McAtee et al., 2013), and IAA played a key regulating role in fruit retention (Kuang et al., 2012; Xie et al., 2018). Plant growth regulators, such as benzyladenine (Trueman, 2010), aminoethoxyvinylglycine (McFadyen et al., 2012b), and $N-(2-$ Chloro-4-pyridyl)- $N$ '-phenylurea (Zeng et al., 2016), were applied to increase fruit retention of macadamia by foliar spray before or after anthesis. The effects of plant growth regulators on the retention of young fruit were ascribed to improved carbohydrate availability ( $\mathrm{Li}$ et al., 2015; Zeng et al., 2016). Moreover, IAA- and CTK-induced fruit set has been reported by inhibition of ethylene production and downregulation of ethylene biosynthesis and response genes (Martínez et al., 2013; Shinozaki et al., 2015). In fact, ethylene and abscisic acid (ABA) were shown to be involved in fruit abscission induced by carbohydrate starvation stress (Botton et al., 2011; Iglesias et al., 2006; Li et al., 2015).

Girdling, defined as the removal of a ring of bark around the branches or trunk, is an important technique and has been widely used to improve fruit retention and increase fruit yield (Annabi et al., 2019; Goren et al., 2003; Khandaker et al., 2011). The effects of girdling have been related to the interruption of phloem transport pathway, which resulted in the blocking of the downward transport of photosynthates (Urban and Alphonsout, 2007; Wang et al., 2006), basipetal flow of IAA (Dann et al., 1985), and acropetal flow of CTK (Havelange et al., 2000), thereby increasing carbohydrate 
availability for the developing organ above the girdle (Casanova et al., 2009; Rivas et al., 2006) and modifying the hormonal balance in the canopy (Kong et al., 2012; Shivashankara et al., 2019). However, girdling can cause root starvation due to the decrease in carbohydrate supply to the lower part of the girdle and the gradual depletion of root carbohydrate reserves (Goren et al., 2003; Moscatello et al., 2017), while the transport of water and soluble mineral nutrients through xylem is not directly affected.

In macadamia, girdling is also applied to improve fruit set. It has been reported that branch girdling increased the early fruit set (Trueman and Turnbull, 1994b; Williams, 1980) and that repeat trunk girdling increased yield in two out of four seasons (McFadyen et al., 2013). Cormack and Bate (1976) suggested that girdling delayed and mitigated the onset of carbohydrate depletion by reducing the shoot growth of macadamia. However, the physiological mechanism through which girdling affects fruit set and retention is less well understood. To explore the responses of macadamia to girdling at fruit set and determine how fruit retention are affected by girdling, an MBG with the strip width of $6 \mathrm{~mm}$ at the main branch diameter of 6 to $8 \mathrm{~cm}$, differed from the previous reports of branch girdling using a wider girdle to the smaller branch (Trueman and Turnbull, 1994b; Williams, 1980), was performed after fruit set, and the effects of MBG on fruit retention and the contents of carbohydrates and endogenous hormones were examined during the early fruit development of macadamia.

The objectives of this study were 1) to test the efficacy of MBG in mitigating the early fruit drop and 2) to determine how MBG affected the status of carbohydrates and endogenous hormones in the leaves, bearing shoots and fruits, with an attempt to assess the relationship between fruit retention and the levels of carbohydrates and endogenous hormones when MBG was performed on macadamia trees.

\section{Materials and Methods}

Plant materials. The experiment was conducted in a mature macadamia orchard located at South Subtropical Crops Research Institute (lat. $21^{\circ} 27^{\prime} \mathrm{N}$, long. $110^{\circ} 32^{\prime} \mathrm{E}, 65 \mathrm{~m}$ a.s.l.), Zhanjiang, China, from March to June 2019. The climate is subtropical, with a mean annual rainfall of $1600 \mathrm{~mm}$ and mean annual temperature of $23^{\circ} \mathrm{C}$. In the orchard with a lateritic soil of medium fertility, trees of macadamia variety 'Nanya-2' (Macadamia integrifolia) grafted on 'Hinde' rootstock were grown at $5 \times 6 \mathrm{~m}$. Irrigation and fertigation were performed according to local practices and pests were controlled when necessary. Eight 9-year-old trees with similar canopy size and initial fruit set were selected for the experiment, which were performed with eight replicates using individual trees as the experimental block.

Main branch girdling and sample collection. Six main branches with similar size and initial fruit set at different positions of the canopy were chosen from each tree at $25 \mathrm{~d}$ after anthesis. Three were girdled at branch diameter of 6 to $8 \mathrm{~cm}$ using a single-blade knife. Two separate circular cuts, $6 \mathrm{~mm}$ apart, were carefully made by a vernier caliper, and the outer bark and phloem tissues around branch were removed. The remaining three branches were used as the control. For each branch, 60 similar sized racemes with comparable initial fruit set were selected, wherein 30 were used for recording the fruit number on each raceme and 30 for fruit sampling. The fruit sampled at regular intervals was separated into the husk and seed, and immediately frozen and ground to fine powder in liquid nitrogen and stored at $-80^{\circ} \mathrm{C}$ for analyses. Additionally, two bearing shoots with similar diameter size and raceme number were collected from each branch, and then the mature leaves at the second and third nodes from the top of the bearing shoots and the stems of these bearing shoots were sampled every $10 \mathrm{~d}$ until $30 \mathrm{~d}$ after treatment when the girdle healed. After washing with pure water and drying in shadow, these leaf and stem samples were heated at $105^{\circ} \mathrm{C}$ for $20 \mathrm{~min}$ to denature enzymes and then ovendried for $\approx 60 \mathrm{~h}$ at $60^{\circ} \mathrm{C}$ to a stabilized dry weight, followed by grinding into fine powder for later analysis.

Investigation of fruit set. After MBG treatment, the fruit number on each marked raceme was recorded at 10-d intervals until $30 \mathrm{~d}$ after treatment, and the average number of fruit per raceme, accumulative fruit drop rate, and relative fruit drop rate were determined. The average number of fruit per raceme was calculated as the mean fruit number of all tagged racemes, the accumulative fruit drop rate was the percentage of the total number of fruit drop from the day of treatment against the initial fruit set. The relative fruit drop rate was the percentage of fruit drop during the period between two investigation dates against the fruit number per raceme on the date of the first investigation of the two.

Measurement of the starch content. An aliquot of $0.2 \mathrm{~g}$ of ground powders was homogenized with $10 \mathrm{~mL}$ of $80 \%$ ethanol and incubated in a water bath at $85^{\circ} \mathrm{C}$ for $1 \mathrm{~h}$. Then, the homogenate was centrifuged at $8000 g_{n}$ for 15 min and the supernatant was discarded. After repeating the above-mentioned procedures, the precipitate was extracted with $10 \mathrm{~mL}$ of $80 \%$ $(\mathrm{w} / \mathrm{v})$ calcium nitrate in a boiling water bath for $1 \mathrm{~h}$. After filtration, the filtrate was collected and used to determine the content of starch according to the $\mathrm{I}_{2}-\mathrm{KI}$ method (Deng et al., 2008).

Analysis of carbohydrate composition. The extraction and determination of carbohydrates was performed according to the protocol of Zeng et al. (2016). Sample (0.5 g) was homogenized with $5 \mathrm{~mL}$ of $80 \%$ ethanol and incubated in a water bath at $85^{\circ} \mathrm{C}$ for $20 \mathrm{~min}$. Then, the homogenate was centrifuged at $8000 g_{\mathrm{n}}$ for $20 \mathrm{~min}$ at $4{ }^{\circ} \mathrm{C}$, and the precipitate was extracted again with $5 \mathrm{~mL} 80 \%$ ethanol following the aforementioned procedures. The supernatants of the two centrifuges were combined, adjusted to a volume of $10 \mathrm{~mL}$ with $80 \%$ ethanol, and evaporated at $85^{\circ} \mathrm{C}$ to remove ethanol. The condensate was diluted to $2 \mathrm{~mL}$ with distilled water and filtered. The filtrate was used for high-performance liquid chromatography (HPLC) analysis using 75\% acetonitrile as the mobile phase, which had been ultrasonically degassed for $2 \mathrm{~h}$ before use. A sample volume of $10 \mu \mathrm{L}$, a flow speed of $1.0 \mathrm{~mL} / \mathrm{min}$ and a column temperature of $35^{\circ} \mathrm{C}$ were applied. The used LC-10A HPLC system (Shimadzu Co., Kyoto, Japan) was equipped with an Agilent $\mathrm{NH}_{2}$ chromatographic column $(150 \mathrm{~mm} \times 4.6 \mathrm{~mm})$ and a refractive index detector. The quantification of carbohydrates was performed according to external standard solution calibration. Standard sugars (sucrose, fructose, and glucose) were purchased from Sigma Chemical Co.

Analysis of endogenous hormones. ZR was one of the most abundant cytokinin and occurred at high level in the developing seed, which was involved in promoting apoplastic unloading of assimilates during the early fruit development (Arnau et al., 1999). Here, the extraction, purification, and determination of endogenous levels of ZR, together with IAA, $\mathrm{GA}_{3}$, and $\mathrm{ABA}$, were performed as described in a modified method of enzyme-linked immune sorbent assay (ELISA) (He, 1993; Yang et al., 2001). Samples ground powders ( $0.5 \mathrm{~g}$ each) were homogenized in an ice bath with a small amount of polyvinylpolypyrrolidone and $5 \mathrm{~mL}$ phosphate buffer solution (PBS; $50 \mathrm{mmol} / \mathrm{L}, \mathrm{pH} 7.5$ ) containing $80 \%$ methanol and $1 \mathrm{mmol} / \mathrm{L}$ butylated hydroxytoluence. After centrifuging at $8000 g_{\mathrm{n}}$ for 20 min at $4{ }^{\circ} \mathrm{C}$, and the supernatant was passed through a $\mathrm{C}_{18}$ Sep-Pak cartridge (Waters Corp., Millford, MA), which was prewashed successively with $10 \mathrm{~mL} 100 \%$ and $5 \mathrm{~mL}$ $80 \%$ methanol. The hormone fractions were dried under $\mathrm{N}_{2}$ and then dissolved with $2 \mathrm{~mL}$ PBS $(50 \mathrm{mmol} / \mathrm{L}, \mathrm{pH} 7.5)$ for analysis by ELISA.

The mouse monoclonal antigen and antibodies against IAA, $\mathrm{GA}_{3}, \mathrm{ZR}$, and $\mathrm{ABA}$, and immunoglobulin $\mathrm{G}$-horse radish peroxidase used in ELISA assays were produced by the Phytohormones Research Institute, China Agricultural University, China (He, 1993). The quantification of these endogenous hormones was performed using standard curves, which were all generated at high coefficients of quadratic correlation $\left(R^{2}>0.998\right)$.

Statistical analysis. Statistical analyses of data were performed using SPSS software (Version 11.5.0; SPSS Inc., Chicago, IL). Differences between treatment and control were analyzed using the procedure of independentsample $t$ test, and the least significant difference $(P<0.05)$ was applied to compare data.

\section{Results}

Effect of MBG on young fruit abscission. Fruit number on the racemes decreased clearly during the early fruit development of macadamia $(P<0.05)$, and MBG treatment at $25 \mathrm{~d}$ after anthesis improved the retention of young fruit. The average number of fruit per raceme was 2.27 at $30 \mathrm{~d}$ after treatment (55 d after anthesis), which was 1.7-fold greater than the control (Fig. 1A). During the 
A

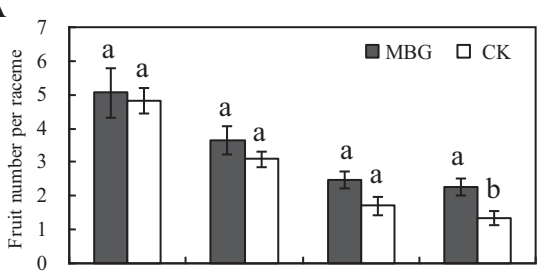

B

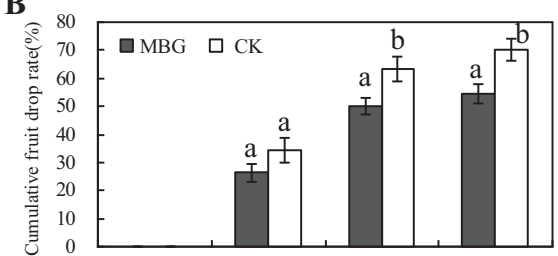

C

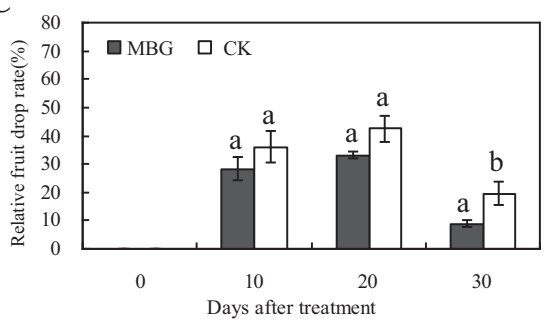

Fig. 1. Effect of main-branch girdling (MBG) treatment on (A) fruit number per raceme, (B) cumulative fruit drop rate, and (C) relative fruit drop rate in macadamia. Data are the means \pm SE of eight replicates. Different letters at each individual time point indicated significant differences between treatment and control (CK) by Student $t$ test at $P<0.05$.

$20 \mathrm{~d}$ after MBG treatment, the accumulative fruit drop rate in the treated trees increased rapidly to $49.9 \%$, which was significantly $(P<0.05)$ lower than $63.3 \%$ in the control (Fig. 1B). From 20 to $30 \mathrm{~d}$ after treatment, the rate of the accumulative fruit drop in the treatment remained significantly $(P<0.05)$ lower than that in the control, but the increment of the accumulative fruit drop rate in the treated trees was only $4.7 \%$ during this period, which was obviously lower than $6.8 \%$ in the control. The relative fruit drop rate in the treatment increased to a peak value of
$33.2 \%$ within the $20 \mathrm{~d}$ after treatment, which was lower than that in the control $(42.4 \%)$, but an insignificant level was found between the treatment and the control. Subsequently, the relative fruit drop rate rapidly reduced to $9.0 \%$ from 20 to $30 \mathrm{~d}$ after treatment, which was significantly $(P<0.05)$ lower than $19.6 \%$ in the control (Fig. 1C). These results suggested that a severe fruit drop of macadamia occurred in the period of early fruit development, and MBG could effectively relieve the early fruit abscission.

Effect of MBG on starch contents in leaves and bearing shoots. The changes of starch in the leaves (Fig. 2A) and bearing shoots (Fig. 2B) of MBG treatment showed a similar pattern to those in the control, decreasing initially and increasing later. However, the starch contents in the leaves did not change obviously until $30 \mathrm{~d}$ after treatment when the level of starch in the treatment were significantly $(P<0.05)$ higher than that in the control. In the case of bearing shoots, the minimum in the treated bearing shoots occurred at day 10 after treatment, which was $10 \mathrm{~d}$ earlier than that in the control. Compared with the control, MBG treatment significantly $(P<0.05)$ reduced the starch content at $10 \mathrm{~d}$ after treatment, but increased it during 20 to $30 \mathrm{~d}$ after treatment (Fig. 2B). The results indicated that MBG promoted the accumulation of carbon nutrition in the leaves and the bearing shoots.

Effect of $M B G$ on carbohydrates in fruit tissues. During the early fruit development, the contents of glucose in both the husk and the seed decreased (Fig. 3A and D), whereas those of fructose increased steadily (Fig. 3B and E). Compared with the control, MBG significantly $(P<0.05)$ increased glucose content in the seed at $30 \mathrm{~d}$ after treatment, and also in the husk at day 10 and day 30. Similarly, fructose level in the husk was also significantly $(P<0.05)$ increased by MBG at day 20 after treatment, as well as that in the seed at 10 to $30 \mathrm{~d}$ after treatment. In addition, sucrose contents in the husk and seed displayed an increasing trend in the treatment, but an opposite change was found in the control (Fig. 3C and F). Further, the contents of sucrose in both the husk and the seed were significantly
$(P<0.05)$ enhanced by MBG within 20 to 30 $\mathrm{d}$ after treatment. The results suggested that MBG produced a large impact on the sugar composition in both the husk and the seed.

Effect of $M B G$ on the endogenous hormones in fruit tissues. The levels of IAA, ZR, and $\mathrm{ABA}$ in the husk gradually decreased during the early fruit development, and $\mathrm{MBG}$ treatment increased the IAA content but decreased the ABA level significantly $(P<$ $0.05)$ at day 30 after treatment, whereas the content of ZR was not influenced by MBG (Fig. $4 \mathrm{~A}, \mathrm{~B}$, and $\mathrm{D}$ ). The change in $\mathrm{GA}_{3}$ content in the husk showed a pattern of decreasing initially and increasing later in both the control and the treatment (Fig. 4C). However, the level of $\mathrm{GA}_{3}$ in the treatment was significantly $(P<0.05)$ higher than that in the control in the period from 20 to $30 \mathrm{~d}$ after treatment.

Unlike the husk, the change patterns of IAA, $\mathrm{GA}_{3}$, and $\mathrm{ABA}$ in the seed were similar in the control and the treatment, decreasing initially and increasing later (Fig. 5A, C, and D). However, MBG treatment significantly enhanced $\mathrm{GA}_{3}$ content $(P<0.05)$ at day 10 and day 30 after treatment and decreased ABA level at $30 \mathrm{~d}$ after treatment. Although IAA content in the treatment was generally augmented relative to that of the control, no significant difference was found after MBG treatment. The content of ZR in the seed exhibited an increasing trend in both the treatment and the control, and the ZR level in the treatment was significantly $(P<0.05)$ higher than that in the control at $30 \mathrm{~d}$ after treatment (Fig. 5B).

Compared with the control, MBG generally enhanced the ratios of (IAA $\left.+\mathrm{GA}_{3}+\mathrm{ZR}\right) /$ ABA in both the husk and the seed, and the increase was significant $(P<0.05)$ at $30 \mathrm{~d}$ after treatment in the husk and at day 10 and day 30 in the seed (Fig. 6). These results suggested that MBG exerted a great effect on the composition and proportion of the endogenous hormones in the early fruit.

\section{Discussion}

The immature fruits of macadamia shed severely during the early fruit development. In
A

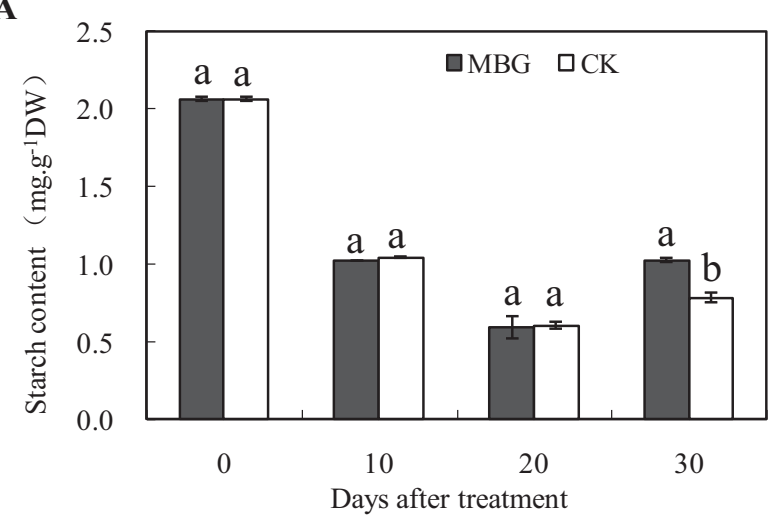

B

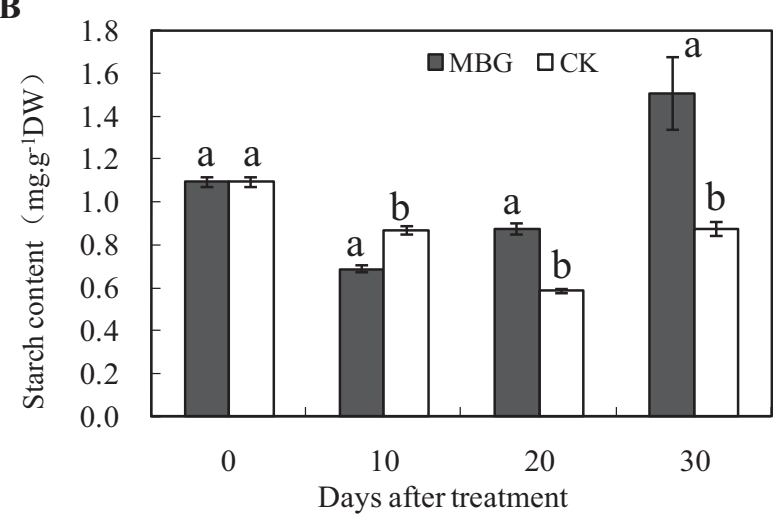

Fig. 2. Effect of main-branch girdling (MBG) treatment on the starch contents in (A) leaves and (B) bearing shoots of macadamia. Data are the means \pm SE of eight replicates. Different letters at each individual time point indicated significant differences between treatment and control (CK) by Student $t$ test at $P<0.05$. 
A

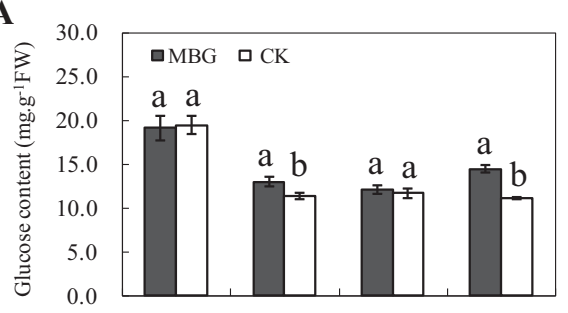

D

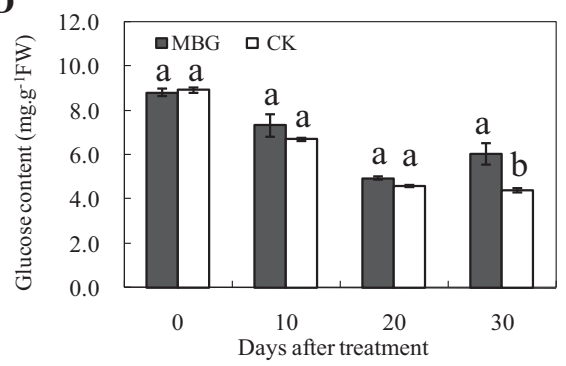

B

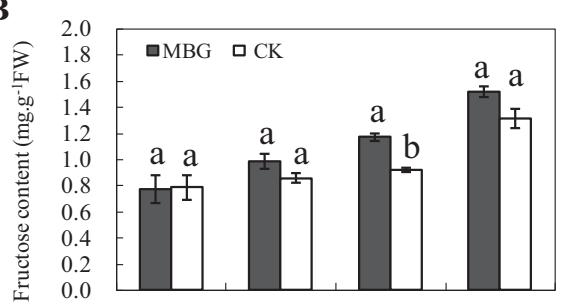

C

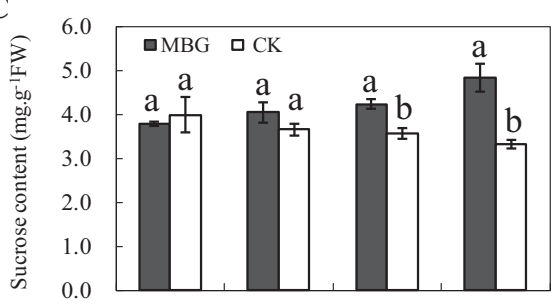

$\mathbf{E}$

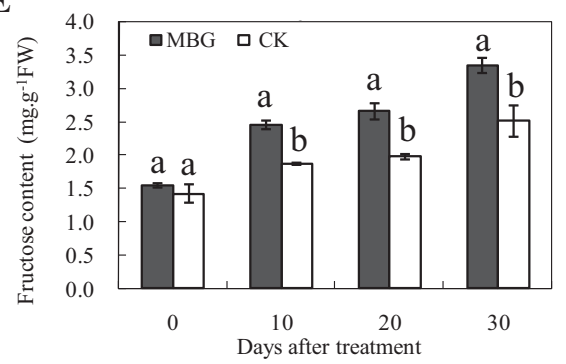

$\mathbf{F}$

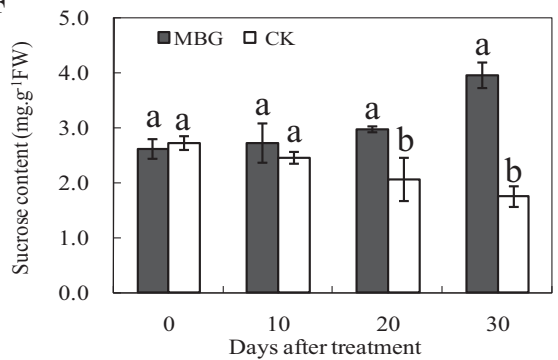

Fig. 3. Effect of main-branch girdling (MBG) treatment on the contents and composition of carbohydrates in the (A-C) husk and (D-F) seed of macadamia. Data are the means \pm SE of eight replicates. Different letters at each individual time point indicated significant differences between treatment and control (CK) by Student $t$ test at $P<0.05$.

the current study, fruit set from $25 \mathrm{~d}$ after anthesis was investigated and the wave of fruitlet drop occurring in the period of 25-45 d after anthesis was confirmed, which resulted in an accumulative fruit drop rate higher than $70 \%$. The results were consistent with previously published reports (Sakai and Nagao, 1985; Tao et al., 2005; Trueman and Turnbull, 1994b; Xu et al., 1995; Zeng et al., 2016).

Girdling is a technique known to increase fruit set in many crops including apple (Hoying and Robinson, 1992), kiwifruit (Boyd and Barnett, 2011), avocado (Trochoulias and O'Neill, 1976), and citrus (Rivas et al., 2006). In the current study, MBG with a 6-mm girdle at fruit set ( $25 \mathrm{~d}$ after anthesis) retained 69\% more fruit per raceme in the following $30 \mathrm{~d}$. This was similar to the effect for girdled macadamia branches using girdle widths of $10 \mathrm{~mm}$ at $7 \mathrm{~d}$ postanthesis (Trueman and Turnbull, 1994b) and $30 \mathrm{~mm}$ (Williams, 1980) in autumn, where the early fruit set increased. Unlike the study in citrus that branch girdling performed at anthesis delayed the natural fruitlet drop (Mahouachi et al., 2009), the MBG did not change the process of fruit drop in macadamia which agreed with the report by Trueman and Turnbull (1994b). Thus, the results indicated that MBG effectively mitigated the early fruit abscission in macadamia.
The amounts of available carbohydrates for fruit growth, especially those of soluble sugars, have been documented to regulate fruit abscission (Botton et al., 2011; Iglesias et al., 2003; Yang et al., 2011). In macadamia, fruit set was also considered to be controlled by available carbohydrates in the tree through a competition mechanism (McFadyen et al., 2011, 2012a, 2013). However, carbohydrate resources within a tree could be manipulated by branch or trunk girdling to minimize competition for resources between fruit and rapidly growing shoots. It has been demonstrated that girdling promoted carbohydrate accumulation above the girdle portion of the tree by preventing the basipetal movement
A

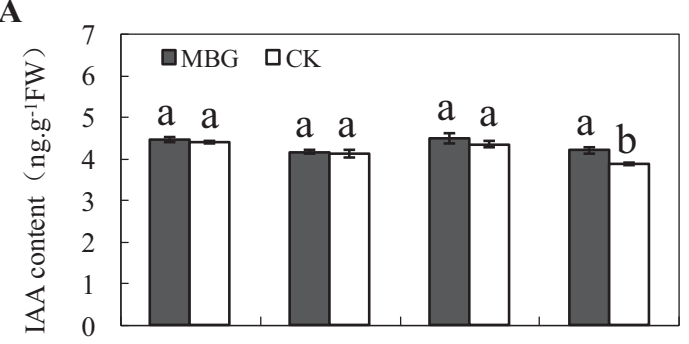

C

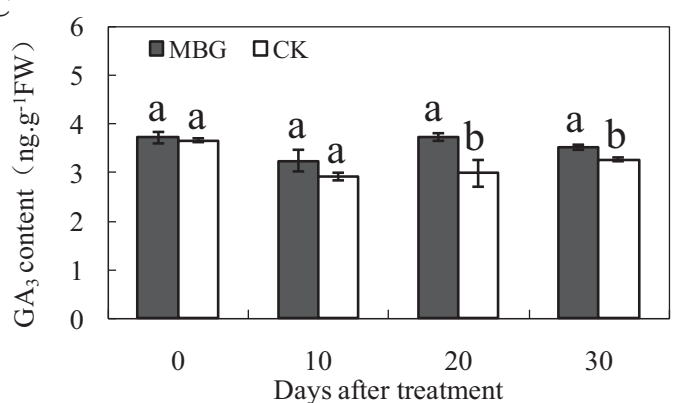

B

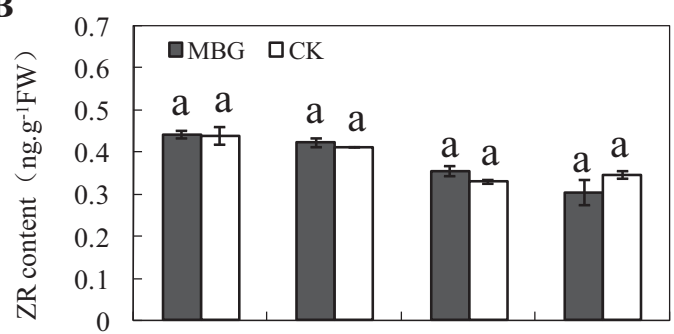

D

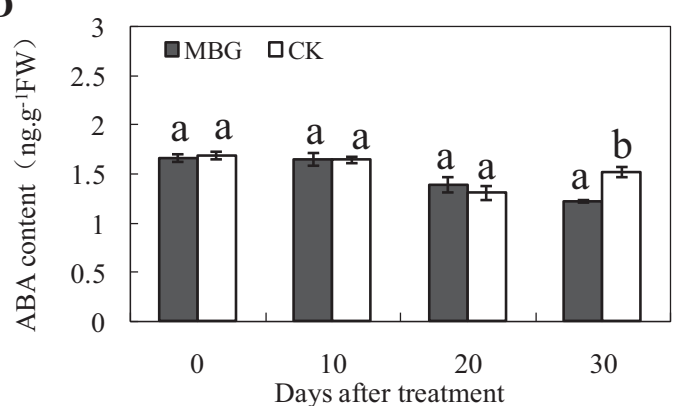

Fig. 4. Effect of main-branch girdling (MBG) treatment on the contents of endogenous (A) indole-3-acetic acid (IAA), (B) zeatin-riboside (ZR), (C) gibberellin $\left(\mathrm{GA}_{3}\right)$, and $(\mathbf{D})$ abscisic acid $(\mathrm{ABA})$ in the husk of macadamia. Data are the means \pm SE of eight replicates. Different letters at each individual time point indicated significant differences between treatment and control (CK) by Student $t$ test at $P<0.05$. 
A

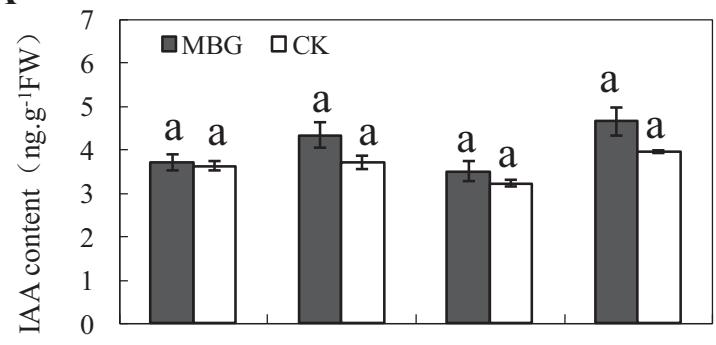

C

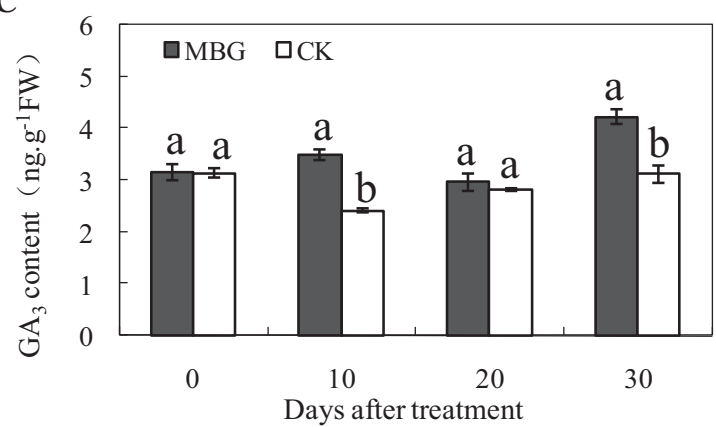

B

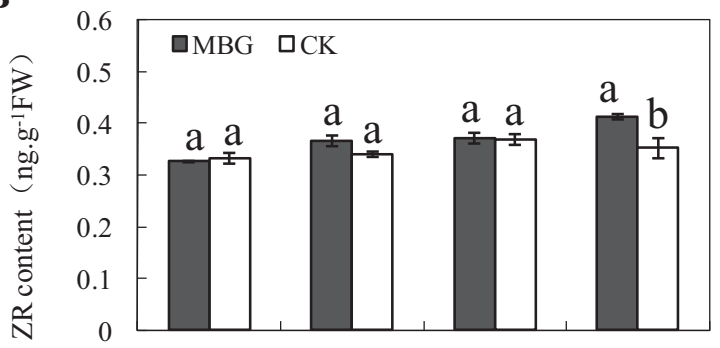

D

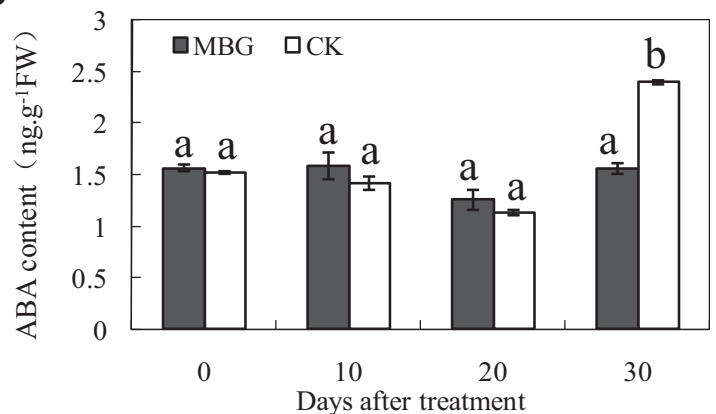

Fig. 5. Effect of main-branch girdling (MBG) treatment on the contents of endogenous (A) indole-3-acetic acid (IAA), (B) zeatin-riboside (ZR), (C) gibberellin $\left(\mathrm{GA}_{3}\right)$, and $(\mathbf{D})$ abscisic acid (ABA) in the seed of macadamia. Data are the means \pm SE of eight replicates. Different letters at each individual time point indicated significant differences between treatment and control (CK) by Student $t$ test at $P<0.05$.

of photosynthetic assimilates through the phloem (Annabi et al., 2019; Quentin et al., 2013; Vemmos et al., 2012). After MBG treatment, the change of starch level in the treated leaves kept pace with that in the control, only at day 30 after treatment $\mathrm{MBG}$ led to a significantly larger accumulation of starch compared with the control. However, starch content in the treated bearing shoots was initially decreased, indicating that early on the leaves might not have been photosynthesizing sufficiently to provide resources which would have come from reserves from other parts of the tree, and as a result of the increased usage from local resources. Subsequently, the content of starch was increased by MBG treatment resulting in more carbon nutrition accumulating in bearing shoots. Hence, MBG increased the content of carbohydrates in both the leaves and the bearing shoots and thus improved the retention of early fruits. Such a response is similar to that reported in citrus
(Mataa et al., 1998) and pistachio (Vemmos et al., 2012).

Developing fruit was considered as the strongest sink for carbohydrates. The overall results on ungirdled branches showed that the total amount of glucose, fructose, and sucrose in the husk and the seed decreased, which might not support the increasing demand of energy source for the growing fruit. After MBG treatment, the levels of these three soluble sugars in both the husk and the seed were significantly increased. Therefore, MBG promoted fruit retention by increasing the carbohydrate level of fruit, suggesting that the availability of carbohydrates in the fruit might be a limiting factor in determining the capability of fruit retention in macadamia tree. Sucrose is the major end-product of photosynthesis, rapidly hydrolyzed to glucose and fructose by invertase activity. A large body of evidence confirmed that glucose and sucrose functioned as both nutrients and signals to regulate fruit development (Botton et al., 2011; Iglesias et al., 2007; Liu et al., 2013; Ruan et al., 2010). In the present study, the contents of glucose and sucrose in the early fruit were significantly increased by $\mathrm{MBG}$, indicating that the improved sugar nutrition in the fruitlets after MBG satisfied fruit growth. Furthermore, the fructose contents in the husk and seed increased steadily in both the treatments, supporting the view that the growing fruit accumulated fructose when sucrose was transported and broken down (Berüter and Feusi, 1997).

Besides carbon nutrition, the endogenous hormones in fruit were involved in regulating fruit abscission (Bangerth, 2000; Gillaspy et al., 1993). As is well known, IAA is essential for fruit retention (Else et al., 2004; Kuang et al., 2012), ethylene and ABA have been implicated in the abscission of young
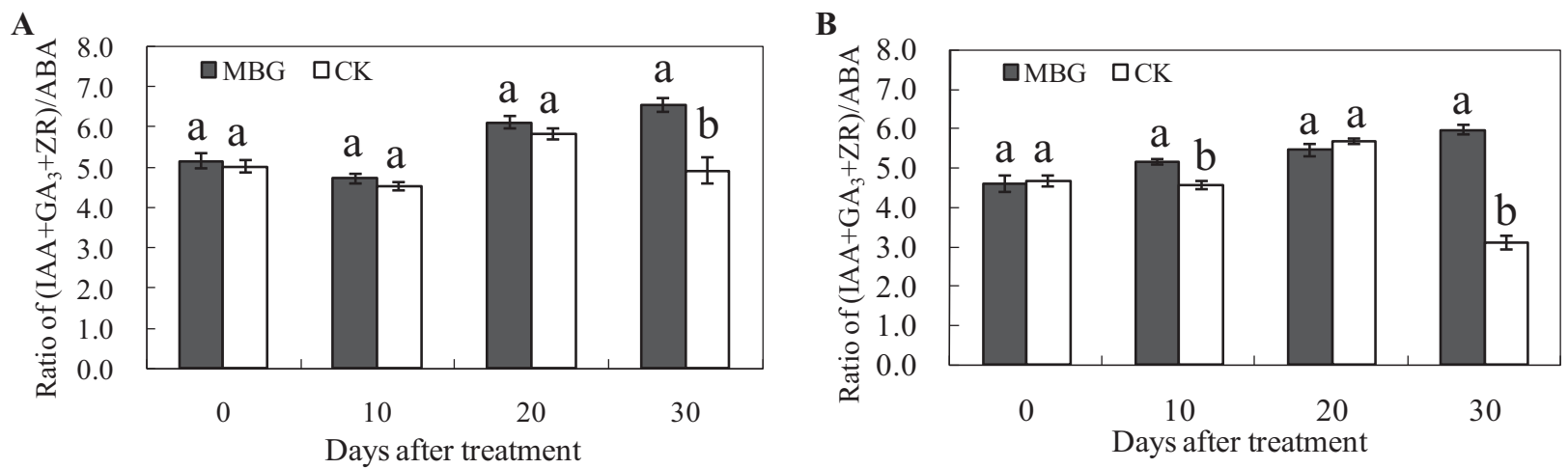

Fig. 6. Changes in the ratio of (IAA $\left.+\mathrm{GA}_{3}+\mathrm{ZR}\right) / \mathrm{ABA}$ in the $(\mathbf{A})$ husk and $(\mathbf{B})$ seed after main-branch girdling $(\mathrm{MBG})$ treatment in macadamia. Data are the means \pm SE of eight replicates. Different letters at each individual time point indicated significant differences between treatment and control (CK) by Student $t$ test at $P<0.05$. IAA $=$ indole-3-acetic acid; $\mathrm{GA}_{3}=$ gibberellin; $\mathrm{ZR}=$ zeatin-ribosid; $\mathrm{ABA}=$ abscisic acid. 
fruit (Blanusa et al., 2006; Eccher et al., 2013; Talon et al., 1997). Xie et al. (2018) reported that IAA was able to inhibit citrus fruitlet abscission by repressing ethylene biosynthesis as a result of the decreased sensitivity of abscission zone to ethylene. In this study, the IAA content in macadamia husk increased remarkably after MBG, accompanied by a significant increase in sugar level. Botton et al. (2011) suggested that the increased sugar in apple served as signal to induce reactive oxygen species burst and cell senescence, resulting in a reduced IAA export and thus increased sensitivity of abscission layers to ethylene. The results of the current study did not support their findings, however.

As a stress hormone, ABA levels in the fruit rise rapidly in response to carbon starvation (Iglesias et al., 2006; Li et al., 2015). Moreover, the increased ABA may serve as a sensor of the intensity of the carbohydrate shortage and function as a regulatory signal during fruit abscission induced by carbon starvation (Gómez-Cadenas et al., 2000). After MBG treatment, the ABA levels in the husk and the seed were significantly lowered, similar to the results previously reported for litchi (Zhou et al., 1999). Therefore, MBG decreased fruit drop by reducing the $\mathrm{ABA}$ level of macadamia fruit, suggesting that ABA signal could be induced by the carbohydrate shortage and that ABA-sugar crosstalk might involved in the process of fruit abscission, which was in agreement with the results reported by Botton et al. (2011) and Zhu et al. (2011). Rivas et al. (2011) showed that girdling, eliciting a higher ABA content in young than in mature leaves, affected differentially the ABA level of citrus leaves. In the fruitlets, peduncle girdling of grape clusters decreased ABA level but increased the physiologically inactive ABA-glucose ester (Böttcher et al., 2018). Soluble sugars above the girdle, especially glucose, might have favored the synthesis of ABA-glucose ester after girdling (Kong et al., 2012; Sauter et al., 2002). The inhibition of fruitlet abscission was ascribed to the depressed ABA biosynthesis and promoted ABA degradation caused by IAA (Xie et al., 2018). Could a decreased ABA in the young fruit of macadamia after MBG be related to the decreased biosynthesis and the raised transportation of IAA to leaves, as well as to the increased ability of degrading ABA and forming $\mathrm{ABA}$ conjugates? It will be of interest to further study the physiological response of ABA in macadamia fruit to girdling.

Commonly, $\mathrm{ZR}$ and $\mathrm{GA}_{3}$ are the most detected endohormones that play an essential role in regulating fruit set and development (Obroucheva, 2014; Qiu et al., 1998; Tyagi et al., 2020). Zhou et al. (2018) reported that girdling increased the contents of $\mathrm{GA}_{3}$ and $\mathrm{ZR}$ in the litchi panicles, which were beneficial to lessen fruit drop. The ZR and GAs levels increased in grape fruitlets after girdling vines (Tyagi et al., 2020). Here, MBG increased remarkably the ZR content in the seed of macadamia, suggesting that a strong sink activity in the fruit was created by MBG via increasing the CTK level of seed to cause diversion of assimilates to the fruit. Mahouachi et al. (2009) stated that the retention of citrus fruitlet by branch girdling was coincided with previous increases in the GAs concentrations. In this study, MBG significantly increased the $\mathrm{GA}_{3}$ levels in husk and seed, indicating that the positive effect of MBG on increasing fruit retention was linked to the concentrations of $\mathrm{GA}_{3}$. Thus, a relationship in the developing fruitlets of macadamia was established between the decreased abscission and the increased levels of $\mathrm{GA}_{3}, \mathrm{ZR}$, and IAA, which is in agreement with the results reported by Qiu et al. (1998), Talon et al. (1997), Mahouachi et al. (2009), and Xie et al. (2018).

Fruit set and development are complex developmental processes that rely on the coordination of different phytohormones (McAtee et al., 2013). Baktir et al. (2004) showed that the relative balance between $\mathrm{GA}_{3}$-like compound and $\mathrm{ABA}$ concentrations of tissues may act as a key regulator of alternate bearing in olive. In the current study, the increase in IAA, $\mathrm{GA}_{3}$, and $\mathrm{ZR}$ contents and the decreased $A B A$ level resulted in the increased ratio of $\left(\mathrm{IAA}+\mathrm{GA}_{3}+\mathrm{ZR}\right) / \mathrm{ABA}$ in the fruit, which could account for the higher fruit retention efficacy of girdling, as reported in litchi (Qiu et al., 1998; Zhou et al., 1999) and citrus (Iglesias et al., 2007; Mahouachi et al., 2009). Therefore, MBG appeared to suppress fruit abscission by modifying the balance of endogenous hormones, although there is a need to perform detailed study on the temporal and spatial role of individual hormones within the fruit after girdling.

In summary, MBG effectively increased fruit retention by increasing the accumulation of carbohydrates in both the leaves and the bearing shoots and by improving the carbohydrate availability in the fruit. Moreover, MBG modified the balance of endogenous hormones and increased the ratio of (IAA $\left.+\mathrm{GA}_{3}+\mathrm{ZR}\right) /$ $\mathrm{ABA}$ in the fruit chiefly by decreasing the ABA level and increasing the IAA, $\mathrm{GA}_{3}$, and ZR levels, which was positive for fruit retention. Therefore, a link in the developing fruit of macadamia was established among the reduction of early abscission rate, the lower level of ABA and the higher concentrations of carbohydrates and growth-promoting hormones induced by MBG.

\section{Literature Cited}

Annabi, K., I. Laaribi, H. Gouta, F. Laabidi, B. Mechri, L. Ajmi, I. Zouari, A. Muscolo, M.R. Panuccio, and M.A. Mezghani. 2019. Protein content, antioxidant activity, carbohydrates and photosynthesis in leaves of girdled stems of four olive cultivars. Scientia Hort. 256:108551, https://doi.org/10.1016/j.scienta.2019.108551.

Arnau, J.A., F.R. Tadeo, J. Guerri, and E. Primo-Millo. 1999. Cytokinins in peach: Endogenous levels during early fruit development. Plant Physiol. Biochem. 37(10):741-750, https://doi.org/10.1016/ s0981-9428(00)86687-5.

Baktir, I., S. Ulger, L. Kaynak, and D.G. Himelrick. 2004. Relationship of seasonal changes in endogenous plant hormones and alternate bearing of olive trees. HortScience 39(5):987-990, https:// doi.org/10.21273/HORTSCI.39.5.987.
Bangerth, F. 2000. Abscission and thinning of young fruit and their regulation by plant hormones and bioregulators. Plant Growth Regulat. 31:43-59, https://doi.org/10.1023/A:1006398513703.

Berüter, J. and M.E.S. Feusi. 1997. The effect of girdling on carbohydrate partitioning in the growing apple fruit. J. Plant Physiol. 151(3):277-285, https://doi.org/10.1016/s0176-1617(97)80253-2.

Blanusa, T., M.A. Else, W.J. Davies, and C.J. Atkinson. 2006. Regulation of sweet cherry abscission: The role of photoassimilation, sugars and abscisic acid. J. Hort. Sci. Biotechnol. 81:613-620, https://doi.org/10.1080/14620316. 2006.11512113.

Böttcher, C., P.K. Boss, K. Harvey, C. Burbidge, and C. Davies. 2018. Peduncle-girdling of Shiraz (Vitis vinifera L.) bunches and sugar concentration at the time of girdling affect wine volatile compounds. Aust. J. Grape Wine Res. 24: 206-218, https://doi.org/10.1111/ajgw.12319.

Botton, A., G. Eccher, C. Forcato, A. Ferrarini, M. Begheldo, M. Zermiani, S. Moscatello, A. Battistelli, R. Velasco, B. Ruperti, and A. Ramina. 2011. Signalling pathways mediating the induction of apple fruitlet abscission. Plant Physiol. 155:185-208, https://doi.org/10.1104/ pp.110.165779.

Boyd, L.M. and A.M. Barnett. 2011. Manipulation of whole-vine carbon allocation using girdling, pruning, and fruit thinning affects fruit numbers and quality in kiwifruit. J. Hort. Sci. 46:590-595, https://doi.org/10.21273/HORTSCI.46.4.590.

Casanova, L., D. González-Rossia, R. Casanova, and M. Agustí. 2009. Scoring increases carbohydrate availability and berry size in seedless grape 'Emperatriz'. Scientia Hort. 122:62-68, https://doi.org/10.1016/j.scienta.2009.03.027.

Cormack, D.B. and G.C. Bate. 1976. Seasonal fluctuation of total non-structural carbohydrate levels within the Macadamia integrifolia cultivar Kakea and its relation to shoot extension. Rhod Zambia Mal J. Agr. Res. 14:39-45.

Dann, I.R., P.H. Jerie, and D.J. Chalmers. 1985. Short-term changes in cambial growth and endogenous IAA concentrations in relation to phloem girdling of peach, Prunus persica (L.). Batch. Aust. J. Plant Physiol. 12:392-402.

Deng, X., Y.W. Mo, H. Tian, J.Y. Chen, J.H. Xie, W.Y. Luo, and J.B. Su. 2008. Effect of girdling on nitrogen assimilation capacity and sugar accumulation in the leaves of Indian Jujube. Chin. J. Trop. Crops 29:541-545 (in Chinese with English abstract), https://doi.org/10.1509/ jimk.16.3.108

Eccher, G., A. Botton, M. Dimauro, A. Battistelli, B. Ruperti, and A. Ramina. 2013. Early induction of apple fruit drop is characterized by an increase of both isoprene emission and abscisic acid content. Plant Physiol. 161(4):112-120, https://doi.org/10.1104/pp.112.208470.

Else, M.A., A.P. Stankiewicz-Davies, C.M. Crisp, and C.J. Atkinson. 2004. The role of polar auxin transport through pedicels of Prunus avium $\mathrm{L}$. in relation to fruit development and retention. J. Expt. Bot. 55:2099-2109, https:// doi.org/10.1093/jxb/erh208.

Gillaspy, G., H. Ben-David, and W. Gruissem. 1993. Fruits: A developmental perspective. Plant Cell 5:1439-1451, https://doi.org/10.1105/ tpc.5.10.1439.

Goetz, M., L.C. Hooper, S.D. Johnson, J.C. Rodrigues, A. Viviansmith, and A.M. Koltunow. 2007. Expression of aberrant forms of AUXIN RESPONSE FACTOR8 stimulates parthenocarpy in arabidopsis and tomato. Plant Physiol. 145(2):351-366, https://doi.org/10.1104/ pp.107.104174. 
Gómez-Cadenas, A., J. Mehouachi, F.R. Tadeo, E. Primo-Millo, and M. Talon. 2000. Hormonal regulation of fruitlet abscission induced by carbohydrate shortage in citrus. Planta 210:636-643, https://doi.org/10.1007/s004250050054.

Goren, R., M. Huberman, and E.E. Goldschmidt. 2003. Girdling: Physiological and horticultural aspects. Hort. Rev. 30:1-36, https://doi.org/ 10.1002/9780470650837.ch1.

Havelange, A., P. Lejeune, and G. Bernier. 2000. Sucrose/cytokinin interaction in Sinapis alba at floral induction: A shoot-to-root-to-shoot physiological loop. Physiol. Plant. 109:343-350, https:// doi.org/10.1034/j.1399-3054.2000.100316.x.

He, Z. 1993. Enzyme linked immunosorbent assay for endogenous plant hormones: Guidance to Experiment on Chemical Control in Crop Plant. Beijing Agricultural University Publishers, Beijing, China (in Chinese).

Hoying, S.A. and T.L. Robinson. 1992. Effects of chain saw girdling and root pruning of apple trees. Acta Hort. 322:167-172, https://doi.org/ 10.17660/actahortic.1992.322.18.

Iglesias, D.J., F.R. Tadeo, E. Primo-Millo, and M. Talon. 2003. Fruit set dependence on carbohydrate availability in citrus trees. Tree Physiol. 23:199-204, https://doi.org/10.1093/treephys/ 23.3.199.

Iglesias, D.J., F.R. Tadeo, E. Primo-Millo, and M. Talon. 2006. Carbohydrate and ethylene levels related to fruitlet drop through abscission zone A in citrus. Trees (Berl.) 20:348-355, https:// doi.org/10.1007/s00468-005-0047-x.

Iglesias, D.J., M. Cercos, J.M. Colmenero-Flore, M.A. Naranjo, G. Rios, E. Carrera, O. RuizRivero, I. Lliso, R. Morillon, F.R. Tadeo, and M. Talon. 2007. Physiology of citrus fruiting. Braz. J. Plant Physiol. 19(4):333-362, https:// doi.org/10.1590/S1677-04202007000400006.

Ito, P.J. 1980. Effect of style removal on fruit set in Macadamia. HortScience 15:520-521, https:// doi.org/10.1007/BF00023230.

Khandaker, M.M., A.S. Hossain, N. Osman, and A.N. Boyce. 2011. Application of girdling for improved fruit retention, yield and fruit quality in Syzygium samarangense under field conditions. Intl. J. Agr. Biol. 13:18-24, https://doi. org/10.1071/CP10309.

Kong, L., P. von Aderkas, S.J. Owen, B. Jaquish, J. Woods, and S.R. Abrams. 2012. Effects of stem girdling on cone yield and endogenous phytohormones and metabolites in developing long shoots of Douglas-fir (Pseudotsuga menziesii). New For. 43:491-503, https://doi.org/ 10.1007/s11056-011-9294-4.

Kuang, J.F., J.Y. Wu, H.Y. Zhong, C.Q. Li, J.Y. Chen, W.J. Lu, and J.G. Li. 2012. Carbohydrate stress affecting fruitlet abscission and expression of genes related to auxin signal transduction pathway in litchi. Intl. J. Mol. Sci. 13:16084-16103, https://doi.org/10.3390/ijms131216084.

Li, C., Y. Wang, X. Huang, J. Li, H. Wang, and J. Li. 2015. An improved fruit transcriptome and the identification of the candidate genes involved in fruit abscission induced by carbohydrate stress in litchi. Front. Plant Sci. 6:439, https://doi.org/10.3389/fpls.2015.00439.

Liu, Y.H., C.E. Offler, and Y.L. Ruan. 2013. Regulation of fruit and seed response to heat and drought by sugars as nutrients and signals. Front. Plant Sci. 4:282, https://doi.org/10.3389/ fpls.2013.00282.

Mahouachi, J., D.J. Iglesias, M. Agustí, and M. Talon. 2009. Delay of early fruitlet abscission by branch girdling in citrus coincides with previous increases in carbohydrate and gibberellin concentrations. Plant Growth Regulat. 58:15-23, https:// doi.org/10.1007/s10725-008-9348-6.
Martínez, C., S. Manzano, Z. Megías, D. Garrido, B. Picó, and M. Jamilena. 2013. Involvement of ethylene biosynthesis and signalling in fruit set and early fruit development in zucchini squash (Cucurbita pepo L.). BMC Plant Biol. 13(1):139, https://doi.org/10.1186/1471-2229-13-139.

Mataa, M., S. Tominaga, and I. Kozaki. 1998. The effect of time of girdling on carbohydrate contents and fruiting in Ponkan mandarin (Citrus reticulata Blanco). Scientia Hort. 73:203-211, https://doi.org/10.1016/S0304-4238(98)00086-7.

McAtee, P., S. Karim, R.J. Schaffer, and K. David. 2013. A dynamic interplay between phytohormones is required for fruit development, maturation, and ripening. Front. Plant Sci. 4:79, https://doi.org/10.3389/fpls.2013.00079.

McFadyen, L., D. Robertson, M. Sedgley, P. Kristiansen, and T. Olesen. 2011. Postpruning shoot growth increases fruit abscission and reduces stem carbohydrates and yield in macadamia. Ann. Bot. 107:993-1001, https://doi.org/10.1093/ aob/mcr026.

McFadyen, L., D. Robertson, M. Sedgley, P. Kristiansen, and T. Olesen. 2012a. Time of pruning affects fruit abscission, stem carbohydrates and yield of macadamia. Funct. Plant Biol. 39:481-492, https://doi.org/10.1071/fp11254.

McFadyen, L., D. Robertson, M. Sedgley, P. Kristiansen, and T. Olesen. 2012b. Effects of the ethylene inhibitor aminoethoxyvinylglycine (AVG) on fruit abscission and yield on pruned and unpruned macadamia trees. Scientia Hort. 137:125-130, https://doi.org/10.1016/j.scienta. 2012.01.028.

McFadyen, L., D. Robertson, M. Sedgley, P. Kristiansen, and T. Olesen. 2013. Effects of girdling on fruit abscission, yield and shoot growth in macadamia. Scientia Hort. 164:172-177, https://doi.org/10.1016/j.scienta.2013.09.006.

Moscatello, S., S. Proietti, A. Augusti, A. Scartazza, and A. Battistelli. 2017. Late summer photosynthesis and storage carbohydrates in walnut (Juglans regia L.): Feed-back and feed-forward effects. Plant Physiol. Biochem. 118:618-626, https://doi.org/10.1016/j.plaphy.2017.07.025.

Nagao, M.A. and W.S. Sakai. 1988. Influence of nut age on ethephon-induced abscission of Macadamia. Scientia Hort. 36:103-108, https:// doi.org/10.1016/0304-4238(88)90012-X.

Ning, D., W. Wang, X. He, Z. Fan, and T. Ma. 2019. Development status and SWOT analysis of tree nuts industry in Yunnan province. J. West China Forestry Sci. 48:8-13 (in Chinese), https:// doi.org/10.16473/j.cnki.xblykx1972.2019.02.002.

Obroucheva, N.V. 2014. Hormonal regulation during plant fruit development. Russ. J. Dev. Biol. 45:11-21, https://doi.org/10.1134/ S1062360414010068.

Picken, A.J.F. 2015. A review of pollination and fruit set in the tomato (Lycopersicon esculentum Mill.). J. Hort. Sci. 59(1):1-13, https://doi. org/10.1080/00221 589.1984.11515163.

Qiu, Y., X. Xu, B. Wang, Z. Zhang, and A.Y. Peiyuan. 1998. Endogenous hormone balance in three types of litchi fruit and their fruit set mechanism. J. Fruit Sci. 1:39-43 (in Chinese).

Quentin, A.G., D.C. Close, L.M.H.P. Hennen, and E.A. Pinkard. 2013. Down-regulation of photosynthesis following girdling, but contrasting effects on fruit set and retention, in two sweet cherry cultivars. Plant Physiol. Biochem. 73: 359-367, https://doi.org/10.1016/j.plaphy.2013. 10.014 .

Rivas, F., F. Fornes, M.J. Rodrigo, L. Zacarías, and M. Agustí. 2011. Changes in carotenoids and $\mathrm{ABA}$ content in Citrus leaves in response to girdling. Scientia Hort. 127:482-487, https:// doi.org/10.1016/j.scienta.2010.11.010.
Rivas, F., Y. Erner, E. Alos, M. Juan, V. Almela, and M. Agusti. 2006. Girdling increases carbohydrate availability and fruit-set in citrus cultivars irrespective of parthenocarpic ability. J. Hort. Sci. Biotechnol. 81:289-295, https://doi. org/10.1080/14620316.2006.11512064.

Ruan, Y.L., Y. Jin, Y.J. Yang, G.J. Li, and J.S. Boyer. 2010. Sugar input, metabolism, and signaling mediated by invertase: Roles in development, yield potential, and response to drought and heat. Mol. Plant 3:942-955, https://doi.org/ $10.1093 / \mathrm{mp} / \mathrm{ssq} 044$.

Sakai, W.S. and M.A. Nagao. 1985. Fruit growth and abscission in Macadamia integrifolia. Physiol. Plant. 64:455-460, https://doi.org/ 10.1111/j.1399-3054.1985.tb08522.x.

Sauter, A., K.J. Dietz, and W. Hartung. 2002. A possible stress physiological role of abscisic acid conjugates in root-t-shoot signaling. Plant Cell Environ. 25:223-228, https://doi. org/10.1046/j.1365-3040.2002.00747.x.

Shinozaki, Y., S. Hao, M. Kojima, H. Sakakibara, Y. Ozeki-Iida, Y. Zheng, Z. Fei, S. Zhong, J.J. Giovannoni, J.K. Rose, Y. Okabe, Y. Heta, H. Ezura, and T. Ariizumi. 2015. Ethylene suppresses tomato (Solanum lycopersicum) fruit set through modification of gibberellin metabolism. Plant J. 83(2):237-251, https://doi.org/ $10.1111 /$ tpj. 12882 .

Shivashankara, K.S., G.A. Geetha, and T.K. Roy. 2019. Influence of girdling on flower sex ratio, biochemical constituents, and fruit set intensity in mango (Mangifera indica L.). Biol. Plant. 63:432-439, https://doi.org/10.32615/bp.2019.064.

Stephenson, R.A., B.W. Cull, and J. Stock. 1986. Vegetative flushing patterns of macadamia trees in south east Queensland. Scientia Hort. 30:53-62, https://doi.org/10.1016/0304-4238 (86)90081-6.

Talon, M., F.R. Tadeo, W. Ben-Cheikh, A. GómezCadenas, J. Mehouachi, J. Pérez-Botella, and E. Primo-Millo. 1997. Hormonal regulation of fruit set and abscission in citrus: Classical concepts and new evidence. Acta Hort. 463:209-217, https://doi.org/10.17660/ ActaHortic. 1998.463.24

Tao, L., L.L. Chen, S.B. Ni, and X.Y. He. 2005. Behavior of flowering and fruiting of Macadamia varieties. Chin. J. Tropical Crops 26:12-15 (in Chinese with English abstract), https:// doi.org/Dx.chinadoi.cn/10.3969/j.issn.10002561.2005.03.003

Trochoulias, T. and G.H. O'Neill. 1976. Girdling of 'Fuerte' avocado in subtropical Australia. Scientia Hort. 5:239-242, https://doi.org/10.1016/ 0304-4238(76)90087-X.

Trueman, S.J. 2010. Benzyladenine delays immature fruit abscission but does not affect final fruit set or kernel size of Macadamia. Afr. J. Agr. Res. 5:1523-1530, https://doi.org/10.1016/ S1671-2927(09)60172-3.

Trueman, S.J. and C.G.N. Turnbull. 1994a. Effects of cross-pollination and flower removal on fruit set of Macadamia. Ann. Bot. 73:23-32, https:// doi.org/10.1006/anbo.1994.1003.

Trueman, S.J. and C.G.N. Turnbull. 1994b. Fruit set, abscission and dry matter accumulation on girdled branches of Macadamia. Ann. Bot. 74:667-674, https://doi.org/10.1006/anbo.1994.1169.

Trueman, S.J., S. Richards, C.A. McConchie, and C.G.N. Turnbull. 2000. Relationships between kernel oil content, fruit removal force and abscission in Macadamia. Aust. J. Exp. Agr. 40:859-866, https://doi.org/10.1071/EA00004.

Tyagi, K., I. Maoz, E. Lewinsohn, L. Lerno, S.E. Ebeler, and A. Lichter. 2020. Girdling of table grapes at fruit set can divert the phenylpropanoid pathway towards accumulation of 
proanthocyanidins and change the volatile composition. Plant Sci. 296:110495, https://doi.org/ 10.1016/j.plantsci.2020.110495.

Urban, L. and L. Alphonsout. 2007. Girdling decreases photosynthetic electron fluxes and induces sustained photoprotection in mango leaves. Tree Physiol. 27:345-352, https://doi. org/10.1093/treephys/27.3.345.

Vemmos, S.N., A. Papagiannopoulou, and S. Coward. 2012. Effects of shoot girdling on photosynthetic capacity, leaf carbohydrate, and bud abscission in pistachio (Pistacia vera $\mathrm{L}$.). Photosynthetica 50(1):35-48, https://doi.org/ 10.1007/s11099-012-0003-0.

Wallace, H.M., V. Vithanage, and E.M. Exley. 1996. The effect of supplementary pollination on nut set of Macadamia (Proteaceae). Ann. Bot. 78:765-773, https://doi.org/10.1006/anbo. 1996.0187.

Wang, W.J., Y.G. Zu, H.M. Wang, X.Y. Li, T. Hirano, and T. Koike. 2006. Newly-formed photosynthates and the respiration rate of girdled stems of Korean pine (Pinus koraiensis Sieb. et Zucc.). Photosynthetica 44:147-150, https://doi.org/10.1007/s11099-005-0172-1.

Wilkie, J.D., M. Sedgley, S. Morris, S. Muldoon, and T. Olesen. 2009. Characteristics of flowering stems and raceme position in macadamia. J. Hort. Sci. Biotechnol.
84:387-392, https://doi.org/10.1080/146203 16.2009.11512537.

Williams, R.R. 1980. Control of premature fruit drop in Macadamia integrifolia: Effects of naphthalene acetic acid application, cincturing, and shoot tip removal. Aust. J. Exp. Agr. Anim. Husb. 20:740-742, https://doi.org/10.1071/ea9800740.

Xie, R., T. Ge, J. Zhang, X. Pan, Y. Ma, S. Yi, and Y. Zheng. 2018. The molecular events of IAA inhibiting citrus fruitlet abscission revealed by digital gene expression profiling. Plant Physiol. Biochem. 130:192-204, https:// doi.org/10.1016/j.plaphy.2018.07.006.

Xu, H.S., R.G. Li, J.L. Zhao, Y.Y. Xu, and Z.Q. Chen. 1995. Fruit development and drop of Macadamia integrifolia. Chin. J. Trop. Crops 16(2):78-83 (in Chinese with English abstract).

Yang, J., J. Zhang, Z. Wang, Q. Zhu, and W. Wang. 2001. Hormonal changes in the grains of rice subjected to water stress during grain filling. Plant Physiol. 127:315-323, https://doi. org/10.1104/pp.127.1.315.

Yang, Z.Q., M. Li, X.Y. Zhang, Y. Yu, H.C. Wang, and X.M. Huang. 2011. Effects of starvation stress on fruit drop and sugar metabolism in longan. J. Fruit Sci. 28(3):428-432 (in Chinese with English abstract).

Zeng, H., W. Yang, C. Lu, W. Lin, M. Zou, H. Zhang, J. Wang, and X. Huang. 2016. Effect of CPPU on carbohydrate and endogenous hormone levels in young macadamia fruit. PLoS One 11(7):E0158705, https://doi.org/ 10.1371/journal.pone. 0158705 .

Zheng, S.F., D.X. Zhao, Q.J. Lan, Z.S. Qin and Q.D. Mo. 2011. Investigation on fruit development characteristics and fruit drop of Macadamia nut. Agr. Res. Appl. 133:20-22 (In Chinese with English abstract), https://doi.org/ 10.3969/j.issn.2095-0764.2011.02.006.

Zhou, C., Z. He, B. Yang, G. Li, and L. Yao. 2018. Effect of girdling on litchi foliar nutrient and development of flower and fruit. Guangdong Agri. Sci. 45:34 42 (in Chinese), https:// doi.org/10.16768/j.issn.1004-874X.2018.04.006.

Zhou, X.J., D.Y. Huang, H.B. Huang, and D.Y Wu. 1999. Carbohydrate and endohormone status in relation to fruit set as influenced by trunk spiral girdling of young litchi trees. Acta Hort. Sinica 2:77-80 (in Chinese with English abstract), https://doi.org/10.3321/j.issn: 0513-353X.1999.02.002,

Zhu, H., C.D. Dardick, E.P. Beers, A.M. Callanhan, R. Xia, and R. Yuan. 2011. Transcriptomics of shading-induced and NAA-induced abscission in apple (Malus domestica) reveals a shared pathway involving reduced photosynthesis, alterations in carbohydrate transport and signaling and hormone crosstalk. BMC Plant Biol. 11:138, https://doi.org/10.1186/1471-2229-11-138. 